\title{
\&netsafe
}

netsafe.org.nz

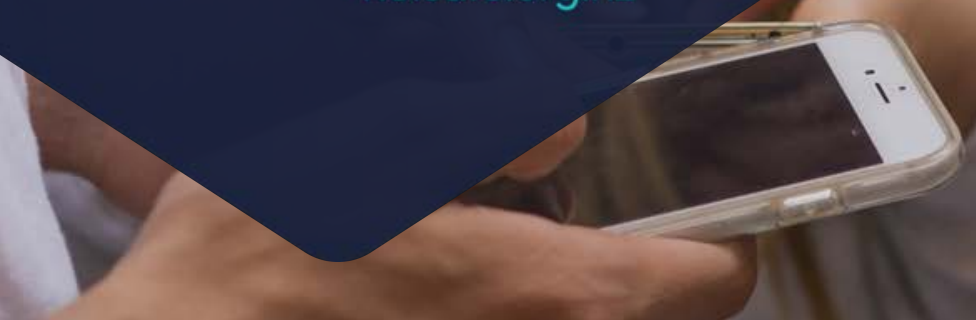

\section{New Zealand teens' digital profile: A factsheet}

\author{
PREPARED BY DR. EDGAR PACHECO AND \\ NEIL MELHUISH
}

\section{What is this about?}

The purpose of this factsheet is to present findings regarding New Zealand teens' use, and attitudes towards, digital technologies and online safety. These findings are part of a larger quantitative study about experiences of risks and harm online. The study is led by Netsafe in partnership with the Ministry for Women.

The factsheet provides government agencies with evidence-based insights that can inform policy development and identify ways to help young New Zealanders manage their digital lives.

\section{What we know so far}

There is a growing body of knowledge, among government agencies and academia, about the way young New Zealanders, teens and children, interact with digital technologies, including the opportunities as well as challenges and potential risks they afford.
Recent examples include the Broadcasting Standards Authority and NZ on Air's (2015) children's media use study. On the other hand, the effects of media representations of sexual violence on teens was the focus of a study by the Office of Film and Literature Classification (2017).

In 2017, a Victoria University study explored the impact of new technologies on the education and learning experiences of children (Lips et al., 2017), while another study (Hartnett, 2017) focused on the differences in digital access and use based on the socioeconomic background of older teenagers.

Netsafe and the Ministry for Women have also investigated aspects of this subject. The Insights into Digital Harm report (2017) is the first qualitative study on teens' perceptions and experiences of digital harm from a gender perspective. A second report entitled Teens and "Sexting" in New Zealand (2017) presents findings from the first quantitative study on the prevalence of the sharing of nude content among teens.

This factsheet adds to the emerging body of knowledge about young people's interaction with digital technologies. While relevant data about adult New Zealanders' use and access to digital technologies have been periodically collected through Auckland University of Technology's World Internet Project NZ 


\section{Summary of findings}

- A third of New Zealand teens (33\%) spend 4 or more hours online in an average day.

- 4 in 10 currently use 5 or more social media platforms.

- 1 in 4 would be devastated if they had no access to digital technologies for a month.

- Nearly 8 in 10 agree "there are a lot of things on the internet that are good for people my age".

- There are gender differences in teens' use of digital devices, the activities they carry out online, and their preferences for specific social media platforms.

- Teens regard themselves as confident technology users. Over 4 in 10 rarely or never seek support regarding an online or technical problem.

- However, Māori and Asian teens are less confident about their digital competencies.

- Overall, teens highly rate their knowledge of online safety, but over 1 in $10(13 \%)$ do not know much about it.

- However, teens with disabilities report lower levels of knowledge regarding online safety.

- Just over half (56\%) agree it is helpful to set age restrictions and block access to content.

- Nearly half (46\%) consider that removing access to the internet or digital devices is an unhelpful safety measure.

- Teens who believe that any protective measures are unhelpful say these actions only affect their learning and study, they will find their way around restrictions, that protective actions are annoying/upsetting, and that they limit their freedom and privacy.
(Smith, Bell, Miller, \& Crothers, 2016) and the Household Use of Information and Communication Technology survey (Statistics New Zealand, 2013), little is known about teens and their engagement with their digital environment as well as their attitudes towards online safety.

\section{What we did}

Data for this study was collected through a nationally representative survey conducted in the third term of the 2017 school year. A total of 1,001 young New Zealanders, aged between 14 and 17, responded to the 15minute questionnaire. Demographic information included age, gender, ethnicity, disability, and the region they lived in.

Netsafe, with feedback from the Ministry for Women, planned and designed the research instrument. Data collection and initial analysis was carried out by Colmar Brunton. Strict procedures were followed to ensure the protection of participants' privacy and confidentiality. The margin of error of this study is $+/-3.1 \%$ on total results.

\section{What we found}

\section{TEENS' USE OF DIGITAL TECHNOLOGIES}

Digital technologies are an important part of New Zealand teens' everyday lives. While they use a range of digital devices to connect (e.g., desktop computer, game console or smart TV) they report largely using smartphones and laptop computers to go online. This finding shows the preference of New Zealand teens for mobile digital tools.

In terms of gender, there was not a significant statistical difference in the use of smartphones, tablets, and smart TVs. However, males reported more often using desktop computers and game consoles to connect online, while females were more likely to use a laptop than males. 
We asked survey participants about the number of digital devices they typically use to connect online. A majority (59\%) of teens said they use three or more devices, while the rest (41\%) connect online through one or two devices. There was, however, a significant difference between genders. Males (65\%) were more likely to use three or more devices than females (52\%).

The average daily time spent online by a third of teens (33\%) is 4 or more hours, nearly 4 in 10 (38\%) are online for between 2 and 4 hours, and $20 \%$ for 1 to 2 hours. The remaining responses (9\%) either spend 1 hour or less or were unsure about how much time they were online for.

We wanted to know the level of participants' affinity with digital technologies. Interestingly, one in four $(25 \%)$ responded they would be "devastated" if they could not use any digital technology for a month, $30 \%$ of respondents mentioned they would miss digital technologies "quite a lot", and 34\% would feel "annoyed but get used to it".

\section{SOCIAL MEDIA PREFERENCES}

Social media encompasses a range of digital tools, from social networking sites (e.g., Facebook) and video-sharing sites (e.g., YouTube) to image messaging applications (e.g., Snapchat). The findings confirm that New Zealand teens are highly engaged with a range of these tools, with 4 in 10 currently using five or more social media tools. When asked which they use most often, 25\% said YouTube, followed by those mentioning Facebook and Snapchat with 23\% each, and Messenger and Instagram (13\% and 11\%, respectively).

In terms of gender, there were some noteworthy differences in the way teens interact with some social media platforms. Males (33\%) used YouTube more often than females (16\%), while the use of Snapchat and Instagram were higher among females, 29\% and $15 \%$ respectively, compared to males $(17 \%$ and $7 \%)$.

Older teens, those aged 16 and 17 years, were more likely than younger (14 and 15 years) to use Facebook, Messenger and Tumblr.

\section{PERCEPTIONS OF THE INTERNET}

We wanted to know participants' views about the internet. The survey included a psychometric question to measure their level of agreement with the following statement: "There are a lot of things on the internet that are good for people my age".

A large majority (79\%) said they agree or strongly agree with the statement, while only $3 \%$ disagreed with it. Overall, male teens (81\%) agreed slightly more with the statement than females (76\%). However, among 14-year-olds, males (83\%) were much more likely to agree than females (65\%). Teens with a disability were less likely to agree with the statement than those with no impairments $(69 \%$ and $80 \%$ respectively).

\section{TEENS' ONLINE ACTIVITIES}

New Zealand teens typically go online for entertainment (e.g., streaming videos or playing games), socialising with others (specifically friends and family), and learning (related to school and other training). Other online activities included searching for information about hobbies and interests, shopping, and news.

We found some differences in terms of gender. Males tended to do more entertainment activities online than females. Females were more likely to go online for learning, shopping, finding out about local activities or participating in cultural or political activities.

The most enjoyable online activities for participants related to entertainment and socialising. However, more males (61\%) enjoyed entertainment activities than females 
(27\%). In contrast, more females (46\%) reported enjoying socialising online than males (29\%). However, these activities are not necessarily exclusive as entertainment activities such as online gaming can also involve social interaction.

\section{TEENS' CONTENT CREATION}

In terms of creating original online content, participants' main activities included sending texts/messages, commenting on other people's social media posts, and posting on their own social media profiles. Other activities included sending email and sharing photos.

Among all these content creation activities, New Zealand teens most enjoyed sending texts/messages to others (47\%), reflecting the importance of socialising activities mentioned above. Other enjoyable activities were posting on their social media profile(s) (15\%), commenting on other people's social media posts (13\%), and live streaming (12\%).

A higher percentage of females (53\%) enjoyed sending texts/messages to others, compared to males (41\%), while live streaming was more enjoyable for males (16\%) than females (7\%).

\section{SELF-REPORTED DIGITAL COMPETENCY}

New Zealand teens are confident with using digital technologies. When asked how often they ask for help or look for information to solve an online or technical problem, over 4 in 10 participants $(43 \%)$ responded that they rarely or never seek support.

However, in terms of ethnicity, Pacific and NZ European/Pakeha teens were more confident about their digital competencies (both groups with 46\%), compared to Māori (39\%) and Asian teens (36\%).

\section{KNOWLEDGE OF ONLINE SAFETY}

The survey included a question regarding online safety. We asked participants to rate their personal knowledge about keeping safe and secure online. For the purposes of the study, this means knowing how to protect themselves and others from online risk or harm. Nearly 3 in 10 participants (29\%) said they know "a lot" about online safety, while $58 \%$ knew "a fair amount". Those who said they knew "not that much" represented $13 \%$ of total responses.

In terms of gender, $32 \%$ of females reported to know "a lot" about online safety, compared to $27 \%$ of males.

A higher percentage of teens with disabilities (21\%) said they knew "not that much" about keeping safe and secure online, compared to teens without impairments (11\%). Also, teens with disabilities (24\%) were less likely to know "a lot" about online safety than their peers without impairments (30\%).

Pacific (26\%) and Māori teens (17\%) reported knowing "not that much" about online safety, in in contrast with other ethnic groups such as European/Pakeha (9\%).

None of the participants said they knew "nothing at all" about online safety.

\section{TEENS' VIEWS ABOUT MEASURES TO KEEP THEM SAFE ONLINE}

We also asked teens to evaluate the helpfulness of different actions or measures intended to keep them safe and secure online.

Over half considered it helpful to block or filter access to websites and other online content (58\%), and to set age restrictions for certain services such as apps, online games and shopping (56\%). This compares to $21 \%$ who thought these actions were unhelpful (the rest of the responses were either unsure or neutral, i.e. neither helpful nor unhelpful).

There was less agreement between the participants about other types of online safety actions. For example, less than half (45\%) of participants said that adults monitoring what 
they do online (e.g., reviewing browsing history), and setting time limits for using devices or being online (40\%) were helpful protective measures. However, the percentage of teens that considered these actions unhelpful was higher in relation to other online safety measures: $26 \%$ said monitoring online activity was unhelpful, and $31 \%$ thought the same in regard to setting time limits.

As previously mentioned, New Zealand teens are highly engaged with a range of digital technologies. So, it was unsurprising to find that nearly half of respondents (46\%) thought taking away access to the internet or a digital device was unhelpful, while $29 \%$ considered it helpful.

The survey included an open-ended question asking those participants to comment on why they thought the protective actions were unhelpful $(n=599)$. The main reasons given were that restrictions to the use of technology will affect their learning and study (11\%), and that teens will find their way to go online behind their parents' backs anyway (11\%). One in ten said protective actions are annoying or upsetting (10\%), and others considered they curbed their freedom (9\%) and privacy (8\%).

Examples of participants' comments are provided - see "In their own words".

\section{Concluding remarks}

In line with prior international research (Boyd, 2014; Lenhart, 2015), the findings confirm that new technologies play an important part in the everyday life of teens. Overall, New Zealand teens consider that technological tools bring several opportunities and benefits that affect the way they socialise, study, and play, among other activities.

However, there are some differences that need a closer look. For instance, the study reveals some gender differences in the devices that male and female teens use to go online, their online activities, and their preferences for specific social media tools.

\section{In their own words}

- "Because teens know how to unblock, people make new accounts, setting time limits doesn't do anything, age limits don't matter, teens still use things with an older age limit and monitoring what we do online doesn't matter, it's called incognito tabs we know how to use them. It blocks recent search history."

Female, 15, NZ European

- "That would not help me understand online safety any better."

Female, 16, Māori

- "Because you now use the internet every day at school to after school with homework and study."

Female, 14, NZ European

- "By taking away access to the internet or a digital device, kids are more likely to do things online behind parents' backs. They'd feel they would need to hide it if something did happen online that was bad."

Female, 16, Another ethnicity

- "Misuse of the internet by others shouldn't mean I be penalised." Male, 16, NZ European

- "Because I am already responsible." Male, 16, NZ European

- "It just creates rebelliousness, frustration and raises conflict and negativity."

Male, 16, Asian

- "Because I think it means they don't trust me and think l'm still a little kid." Female, 15 years, NZ European

- "I don't like having my rights taken away."

Male, 15, Another ethnicity 
These findings are consistent with the results of the Insights into Digital Harm: The Online Lives of New Zealand Girls and Boys, a qualitative study developed last year by the Ministry for Women in partnership with Netsafe.

Similarly, while on average New Zealand teens are confident users of technology, there are noteworthy differences regarding ethnicity. The fact that Māori and Asian teens express less confidence in their digital competencies suggests that there are issues around digital literacy still affecting a young generation of New Zealanders - which could have implications for other issues such as the digital divide (Sylvester, Toland, \& Parore, 2017) and online safety.

In general, the findings show that New Zealand teens perceive they have a reasonable understanding of digital challenges and risks. However, the findings reveal that teens with disabilities' self-reported knowledge of online safety is lower than teens without impairments. This raises concerns about this specific group being the potential target of malevolent online behaviours (Kowalski, Morgan, Drake-Lavelle, \& Allison, 2016) .

In conclusion, while the evidence presented in this factsheet is a step forward in describing New Zealand teens' interactions with their digital environment, we recommend further and contextual research to understand the online behaviour and experiences of specific groups within New Zealand's young population.

\section{What is next?}

The findings in this factsheet are part of a larger representative study focusing on New Zealand teens and their experiences of digital harm and risks. The study is led by Netsafe in partnership with the Ministry for Women and will be released in the second trimester of 2018.
Netsafe and the Ministry for Women have been collaborating since late 2016 and developing research on the topic of online safety and teens with a focus on gender differences. In addition to this factsheet and the upcoming nationally representative study, the partnership has already released up-todate evidence-based contributions through two reports: Insights into Digital Harm and Teens and "Sexting" in New Zealand. In doing so, Netsafe and the Ministry are positioning themselves at the forefront of New Zealand research on young people and online safety.

\section{References}

Boyd, D. (2014). It's complicated: The social lives of networked teens. New Haven: Yale University Press.

Broadcasting Standards Authority, \& NZ On Air. (2015). Children's Media Use Study. Retrieved from http://www.nzonair.govt.nz/research/allresearch/childrens-media-use-study-2015/

Hartnett, M. (2017). Differences in the digital home lives of young people in New Zealand. British Journal of Educational Technology, 48(2), 642-652. https://doi.org/10.1111/bjet.12430

Kowalski, R. M., Morgan, C. A., Drake-Lavelle, K., \& Allison, B. (2016). Cyberbullying among college students with disabilities. Computers in Human Behavior, 57, 416-427. https://doi.org/10.1016/J.CHB.2015.12.044

Lenhart, A. (2015). Teens, social media and technology overview 2015. Retrieved February 8, 2018, from http://www. pewinternet.org/2015/04/09/teens -social-media-technology-2015/

Lips, M., Eppel, E., Mcrae, H., Starkey, L., Sylvester, A., Parore, P., \& Barlow, L. (2017). Understanding children's use and experience with digital technologies. Final research report. Retrieved December 5, 2017, from https://tinyurl.com/y9vkwms9

Ministry for Women. (2017). Insights into digital harm: The online lives of New Zealand girls and boys. Wellington, New Zealand. Retrieved from http://women.govt.nz/documents/insightsdigital-harm-online-lives-new-zealand-girlsand-boys 
Netsafe. (2017). Teens and "sexting" in New Zealand: Prevalence and attitudes. Retrieved from https://www.netsafe.org.nz/wpcontent/uploads/2017/12/SEXTING-NZReport-Dec-7-2017.pdf

Netsafe. (2018). Harmful digital communications in New Zealand. Annual Population Survey 2017. Wellington, New zealand. Retrieved from https://www.netsafe.org.nz/annualpopulation-survey-2017/

Office of Film and Literature Classification. (2017). Young New Zealanders viewing sexual violence. Office of Film and Literature Classification. Wellington, New Zealand. Retrieved from https://www.classificationoffice.govt.nz/asset s/PDFs/report-yp-sv-stage-3-2017.pdf

Smith, P., Bell, A., Miller, M., \& Crothers, C. (2016). Internet trends in New Zealand 20072015. Retrieved September 1, 2017, from https://workresearch.aut.ac.nz/_data/assets/ pdf_file/0004/71329/WIPNZtrends-07-15.pdf

Statistics New Zealand. (2013). Household use of information and communication technology: 2012. Retrieved September 4, 2017, from http://archive.stats.govt.nz/browse_for_stats/i ndustry_sectors/information_technology_and communications/HouseholdUseofICT_HOT $\overline{\mathrm{P}} 2012$.aspx

Sylvester, A., Toland, J., \& Parore, P. (2017). Is the digital divide still relevant in 2017 ? Two cases from marginalised communities in Aotearoa-New Zealand. PACIS 2017 Proceedings. Retrieved from http://aisel.aisnet.org/pacis2017/123

\section{NEW ZEALAND TEENS' DIGITAL PROFILE: A FACTSHEET}

Wellington, New Zealand, February 2018

www.netsafe.org.nz

research@netsafe.org.nz

Recommended citation: Netsafe. (2018). New Zealand teens' digital profile: A Factsheet. Wellington, NZ: Netsafe. Retrieved from: https://www.netsafe.org.nz/youth-factsheet-2018

ISBN: 978-0-473-42899-0

\section{ATTRIBUTION-NONCOMMERCIAL-SHAREALIKE}

https:/ /creativecommons.org/licenses/by-nc-sa/4.0/ [English]

https://creativecommons.org/licenses/by-nc-sa/4.0/legalcode.mi [Te Reo Māori] 